\title{
128. A New Species of Cambarincola, with Remarks on Spermatic Vesicles of Some Branchiobdellid Worms.
}

\author{
By Hideji YamaguchI.
}

Zoological Institute, Faculty of Science, Hokkaido Imperial University, Sapporo.

(Comm. by A. OKA, M.I.A., Nov. 12, 1932.)

The Branchiobdellidae known as occurring in Japan have been represented by the four genera, Branchiobdella, Stephanodrilus, Ceratodrilus $^{1)}$ and Carcinodrilus. ${ }^{2}$ Lately I found among branchiobdellid specimens attached to the crayfish, Cambaroides japonicus, collected at Soranuma, Hokkaido, a new worm referable to the genus Cambarincola which has hitherto been reported only from America. In the preparation of the paper the writer's thanks are due to Prof. Dr. Tohru Uchida who gave him several valuable suggestions and advices.

Cambarincola homodonta nov. sp.

The body is rather slender and cylindrical, about $1.5 \mathrm{~mm}$ long and $0.2 \mathrm{~mm}$ wide in the widest portion about the middle part of the trunk, in mature worms. From the widest portion the body becomes gradually narrower toward both the anterior and posterior ends. The head is easily distinguishable from the trunk, composed of two annulations of which the anterior one is the peristomium indistinctly divided dorsoventrally. The dorsal part of the peristomium is incised to form 4 distinct digitiform appendages or lobules, while the ventral part is slightly bilobed. In addition to these lobules two small ones are located at each lateral part of the peristomium. The mouth is surrounded by a circlet of 16 minute papillae. Both the dorsal and ventral dental plates are slightly brown and of similar form. The teeth of each plate consist of a large median and 8 small lateral ones. Unlike Ceratodrilus and Pterodrilus, the species is destitude of trunk appendages. The spermathecal pore and the male sexual aperture open on a slightly elevated papilla in the mid-ventral line in trunk segment $V$

Contribution No. 41 from the Zoological Institute, Faculty of Science, Hokkaido Imperial University, Sapporo.

1) Ann. Zool. Japon., Vol. 13, No. 4 (1932), pp. 361-367.

2) Jour. Fac. Sci. Hokkaido Univ., Ser. VI., Vol. II, No. I (1932), pp. 61-67. 
and VI respectively. The oviduct pores are paired, situated on the ventro-lateral sides of trunk segment VII. The anterior nephridia open outside in a common median dorsal pore in trunk segment III. The digestive tract runs almost straight from the mouth to the anus. Two pharyngeal diverticula, one dorsal and the other ventral, are present. The testes are paired in trunk segments V and VI. The ovaries are in pair in trunk segment VII. The spermatic vesicle is represented by a long simple tube, irregularly folded about three times and connected with both the anterior and the posterior vasa deferentia at some distance from the distal end. The spermatheca is not bifid, having in the middle portion a flask-shaped enlarged

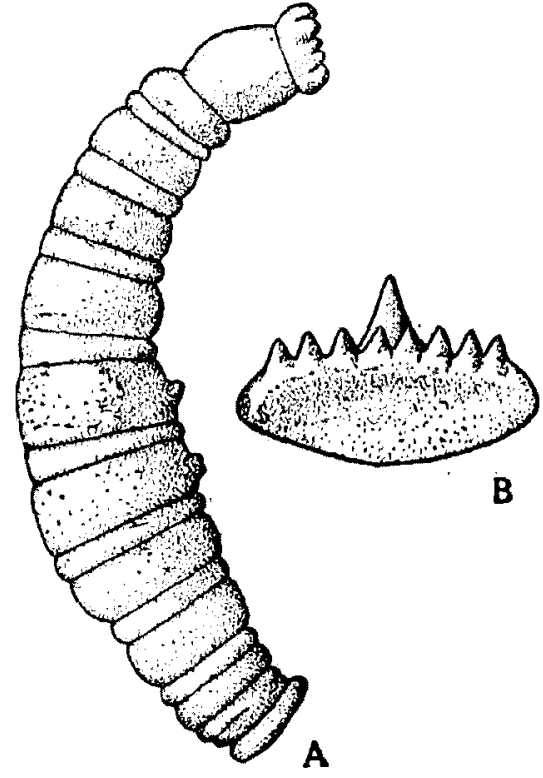

Fig. 1. Cambarincola homodonta nov. sp., A, side view, about $\times 50 ; \mathrm{B}$, dorsal dental plate, about $\times 900$.

part which occasionally shrinks with the distal part withdrawn into the proximal portion.

Remarks: The present species seems to me to be referable to the genus Cambarincola in respect to the following characteristics; the plurilobate peristomium, the paired testes in trunk segments $\mathrm{V}$ and VI, the number of pharyngeal diverticula, possession of a common anterior nephridial pore, absence of trunk appendage. The plurilobate peristomium often occurs in other genera, such as Branchiobdella, ${ }^{1)}$ Ceratodrilus, Stephanodrilus and Carcinodrilus. The common dorsal anterior nephridial pore is found in Bdellodrilus illuminatus but the bifid spermatheca occurring in Bdellodrilus is absent in the new species.

In regard to spermatic vesicles of branchiobdellids there seems to be a series of variations as will be stated below. According to Pierantoni (1912) the vesicles of Branchiobdella anatis is of a simple bulged form and connected with a vas deferens (Fig. 2. A). In Branchiobdella tetrodonta (by Pierantoni, 1912) the vesicle is narrower and provided with a blind tube at the distal end (Fig. 2. B). The vesicle becomes comparatively a little larger in Stephanodrilus sapporensis and is furnished with two vasa deferentia (Fig. 2. C). As regards the spermatic vesicle, the new species is almost similar to the

1) B. digitata and B. minuta. 
former species but differs in the presence of the foldings of the proximal portion (Fig. 2. D). The accessory sperm tube known as a generic character of Cambarincola, seems to me to be homologous to the blind tube of these three species (Fig. 2. E). There is a difference

A
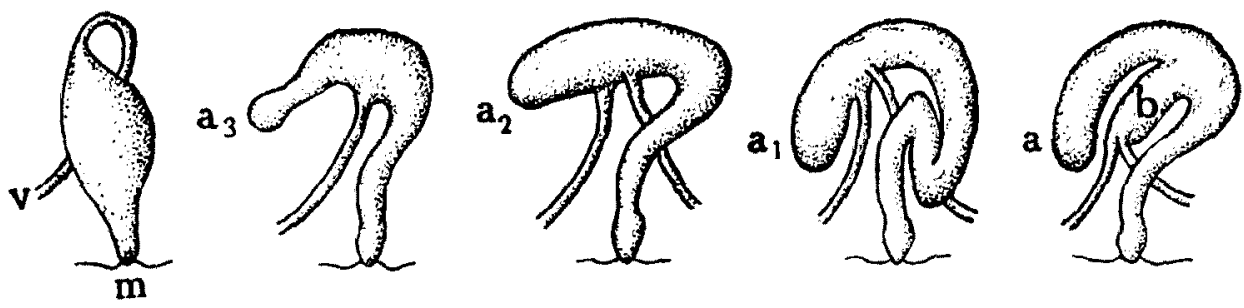

Fig. 2. Shematic figures of spermatic vesicles in various Branchiobdellids. A, Branchiobdella anatis after Pierantoni, slightly changed; B, Branchiobdella tetrodonta after Pierantoni, changed; C, Stephanodrilus sapporensis; D, Cambarincola sp. v, vas deferens; a, accessory sperm tube; $a_{1}, a_{2}, a_{3}$, blind tube; $b$, short tube connected with two vasa deferentia.

in the new species from the other species of Cambarincola hitherto described, in which the spermatic vesicle has always a short tube (Fig. 2. E, b) connected with two vasa diferentia as shown in a section made from Cambarincola ${ }^{1)} \mathrm{sp}$. Moreover, both the dental plates of the new species are almost similar in form, while in other species of Cambarincola they are generally dissimilar.

Though the new species is unique in these two characters, it appears to me to be right to refer the species to the genus Cambarincola.

1) The species was obtained from crayfishes transferred from America in a Japanese lake and is probably referable to $C$. philadelphia. 